\title{
Social Work Education
}

The International Journal

\section{What tools facilitate learning on placement? Findings of a social work student-to-student research study}

\section{Elaine Wilson \& Niamh Flanagan}

To cite this article: Elaine Wilson \& Niamh Flanagan (2019): What tools facilitate learning on placement? Findings of a social work student-to-student research study, Social Work Education, DOI: $10.1080 / 02615479.2019 .1702636$

To link to this article: https://doi.org/10.1080/02615479.2019.1702636

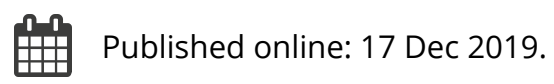

Submit your article to this journal ¿

Џll Article views: 284

Q View related articles $\square$

View Crossmark data ¿

Citing articles: 1 View citing articles $\sqsubset$ 


\title{
What tools facilitate learning on placement? Findings of a social work student-to-student research study
}

\author{
Elaine Wilson (iD) and Niamh Flanagan (iD) ${ }^{\mathrm{b}}$ \\ aSchool of Social Policy, Social Work and Social Justice, University College Dublin, Dublin, Ireland; \\ ${ }^{b}$ Department of Applied Social Studies, Maynooth University, Maynooth, Ireland
}

\begin{abstract}
Social work fieldwork placements are recognized as a core element of professional training. This article analyses the experiences of students who have completed a social work placement, examining tools that facilitated learning on placement. The research utilized an innovative methodology that enabled first-year students to design an online survey which they administered to second-year students. Using this approach students gained research experience, and also an insight into what assisted learning on placement. This two-phase cross-sectional research surveyed a 2014/15 cohort of postgraduate social work (MSW) students. This article focuses on students' perceptions of the tools which assisted learning on placement. The article explores student-driven tools such as self-reflection, writing case notes and critiquing one's own work. Interaction with the practice teacher, supervision and feedback were other tools discussed by the students as well as formal inputs such as induction, training and safety instructions. An interesting finding was that whilst students recognized the importance of self-directed learning, many did not engage in it routinely. Moreover, self-directed learning was, at best, weakly correlated with perceived learning and satisfaction with the placement. In fact, learning and satisfaction were primarily vested in the practice teachers and other external contributors even over and above casework.
\end{abstract}

\section{ARTICLE HISTORY}

Received 23 April 2019

Accepted 4 December 2019

\section{KEYWORDS}

Practice placement; practice learning; social work; student experiences; autonomous learning

\section{Introduction}

Within social work education, fieldwork placement is a crucial element of student learning. It has been described as the environment where the primary learning experiences involve students delivering an agency service to clients or community members (Bogo \& McKnight, 2006, p. 51). It is within fieldwork placements that students learn to apply to practice the theoretical knowledge that they learn in the academic setting. The opportunity to learn by 'doing' (Chui, 2009) results in 'a more profound and lasting impact than classroom teaching' (Bellinger, 2010, p. 2453). Mac Dermott \& Campbell (2016, p. 31-32) note that early references to field education in social work are founded within the apprenticeship model and that they scaffold their learning and development as social work practitioners through direct experience. It is clear, as Bogo and Sewell $(2019$, p. 1) note, that it is not enough for students to just to learn about conceptual knowledge, 
emerging empirical findings, and values in the university setting, but rather it is essential that they learn to integrate and apply these dimensions through skillful and intentional practices.

In the UK, Ireland, Australasia and North America placements are a required and integral component of the social work education curriculum. They are usually organized by the universities, in partnership with statutory, voluntary and community social work agencies. In Ireland, a typical unit of practice placement comprises the student and practice teacher, with a practice tutor acting as the liaison between the university, student and practice teacher. As group supervision in fieldwork placements is uncommon in Ireland, the exclusive nature of the practice teacher, tutor, and student relationship means that students from the same qualifying class can have different learning experiences on placement.

This is the second of two papers from one study, the first of which has been published (Flanagan \& Wilson, 2018).

\section{Literature review}

Social work education is required to provide students with knowledge and teach them the relevant skills to enter the profession. As adult learners, social work students are required to actively engage in the practice learning setting in order to acquire the new skills necessary for their future career as a professional social worker. Students have, as Mac Dermott \& Campbell (2016, p. 32) note, the opportunity on placement to develop their skills of self-reflection, critical decision-making and enhance their understanding of the theoretical concepts of intervention and the demonstration of a critical application of knowledge when working directly with clients. Social work placement providers have both a professional and ethical responsibility to ensure that students are provided with appropriate learning environments which will prepare them to become competent and professional practitioners (Cleak, Hawkins, Laughton, \& Williams, 2015). Although Wilson, Walsh, and Kirby (2008) made the point that the students' perspective on the practice learning experience is crucial, Clare (2007) noted that the student voice tends not to be given as much weight as the other key stakeholders. In Ireland, as is common across the world of social work education, the practice teacher is crucial in ensuring that the student is exposed to a wide range of pedagogical techniques to enhance their learning. The relationship between practice teacher and student has been described as the mediator of important teaching and learning processes (Kourgiantakis, Sewell, \& Bogo, 2019) and it is through these processes that students develop holistic competency.

The placement is where students begin to identify themselves as social workers and internalize the role (Nixon \& Murr, 2006). Observation or 'shadowing' of the practice teacher is a key part of student learning, particularly for those on their first placement. Indeed, Mumm (2006, p. 74) notes that 'students learn best by practicing the skills, second best by having the skills demonstrated for them and the least effective ways are lecture and discussion'. It is concerning to note that despite research (Fortune, McCarthy, \& Abramson, 2001) finding that students who have more opportunities to observe are more satisfied and perform better, Cleak and Smith's Australian study (2012) found that half of all qualifying students did not have regular opportunities to observe social work practice, or have their own practice observed. The opportunity to carry out direct work with clients is also seen as essential for learning (Bogo, 2015) but the practice teacher needs to 
ensure that the student's capabilities match these expectations (Fernandez, 1998). Being assigned work that is beyond the student's ability can lead to the student feeling overwhelmed and, on the other hand, not being trusted to carry out work within their ability can lead to the student feeling demotivated. Constructive feedback from practice teachers is a key element of student learning (Barretti, 2009; Miller, Kovacs, Wright, Corcoran, \& Rosenblum, 2005) and can be seen as a core tool for student learning. It should provide the student with information about what is expected of them in order to meet the required competencies (Goodyear, 2014). Studies have also identified that students believe feedback to be critical to their learning and may even value it more than practice teachers do (Barretti, 2009; Kourgiantakis et al., 2019; Miller et al., 2005).

Although there is widespread agreement about the value of supervision, there is very little literature that examines what is it about the process of supervision that helps the student to learn (Kourgiantakis et al., 2019). Roulston, Cleak, and Vreugdenhil (2018, p. 12) examined the activities that promoted competence and professional identity for social work students on placement and proposed that the ideal supervisory relationship is one where the practice teacher takes responsibility for facilitating regular meetings and generating a safe and supportive learning environment with regular constructive feedback on practice and progress. Lefevre (2005) found that students found a supportive supervisory relationship to be one where the practice teacher was available, encouraging and collaborative, striking the delicate balance between overseeing the student's practice and allowing them to develop their autonomy.

Although placements should provide opportunities for the integration of theoretical learning, very often students do not see the relevance of classroom learning when they are in practice, viewing the placement as 'an apprenticeship dissociated from conceptual learning' (Vayda \& Bogo, 1991, p. 271). Whilst Smith, Cleak, and Vreugdenhil (2015) found that students are sometimes skeptical of practice teachers' confidence in the application of theory to practice, other research found that time was a key factor in enabling students to integrate theory to practice (Rawles, 2016; Simpson, Mathews, Croft, McKinna, \& Lee, 2010). Wilson's (2013) study pointed out how there was a mismatch between the use of case studies in the classroom and the more complex situations which students found when going on placement. Finally, there appear to be contradictory findings about the relationship between satisfaction and learning (McSweeney \& Williams, 2018, p. 585).

\section{Methodology}

This study is part of a wider staff-initiated, student-to-student dialogue project which formed part of an MSW program in the Republic of Ireland (Flanagan \& Wilson, 2018). While the project aimed to initiate a dialogue between first-year and second-year MSW students to ascertain their experiences on placement, and to enable first-year students to develop their research skills, the substantive aim of the study was to analyze the quality of practice learning opportunities which social work students experienced on their fieldwork placements. In order to achieve these aims, the project adopted an experiential-learning approach which has been used effectively in other settings (McIntyre \& Paul, 2013; Rubin, Robinson, \& Valutis, 2010; Wulf-Andersen, Morgensen, \& Hjort-Madsen, 2013). The approach thus casts students as both research-learners, as well as curriculum-learners. Joubert et al.'s (2017) philosophy of engaging social work students in staff-initiated 
research to support and foster research knowledge, competency and confidence were adopted. This approach which combines experiential learning with support, facilitation and collaborative knowledge production holds much potential for the development of research about social work education and learning.

\section{Research setting}

As in most other countries where social work is taught, students in Ireland are required to undertake practice placements. In Irish schools of social work students typically undertake two practice placements of 14-week duration. It is expected that students will integrate theory-based learning acquired in the first semester with their practice placement experience. The placement assessment is devolved to the practice teacher, who gathers evidence using a variety of means, such as direct observation, co-working, reports from other colleagues and minutes of supervision. In addition, both practice teacher and student write a detailed, evidence-based placement report to demonstrate the student's learning. Students are assessed against six standards of proficiency as required by the state regulatory body. The practice teacher is expected to justify a pass/fail recommendation in a report and all recommendations are then assessed under the university's exam process.

\section{Aims, study design and sample}

On completion of their practice placements, a cohort of MSW students were invited to participate in this two-phase, cross-sectional study, the aim of which was to identify tools that assisted their learning. In Phase 1 (2014), a first-year student-staff research team surveyed a convenience sample of second-year students $(\mathrm{N}=37)$. In Phase 2 (2015) staff researchers surveyed both first-year and second-year students $(N=95)$. Thus, second-year students participated twice, after each of their practice placements. The final sample of 100 responses represents a $90 \%$ response rate from first-year students and $60 \%$ from second years.

\section{Ethical review}

Ethical approval for the study was awarded by the University Human Research Ethics Committee. The research participants were students of programs in which the researchers are lecturers. As there was a potential power imbalance, students were informed both in writing and in research information sessions that participation was voluntary and would not affect their progress on the program in any way. In order for students not to feel coerced into participating all responses were anonymous.

\section{Reviewing literature}

A preliminary literature review conducted by the authors formed the basis for student review of selected literature. Blogs and in-class discussion forums were used to elucidate understanding of the variation in practice learning tools. This prompted exploration of the key tools which would be researched. 


\section{Data collection and analysis}

An e-survey of tools for learning on placement was designed by first-year students in collaboration with the authors. Tools identified in student reviews of literature were assigned to student-teams who developed both open and closed questions about each tool. Questions were also included in the dependent variables of perceived satisfaction and success of the placement.

The Phase 1 survey was administered via an online survey instrument yielding a 77\% $(n=37)$ response rate from second-year students. Descriptive frequency tables were returned to first-year student groups for thematic analysis. Data from the Phase 1 survey were written up by first-year student groups in a Wikispaces Classroom, an online social writing platform for education. This was subsequently redrafted into a poster and presented by students at the Irish Association of Social Workers' conference (first Year M Soc Sc (Social Work) Students, Flanagan \& Wilson, 2015). Because Phase 1 of the study was designed as a student-to-student dialogue project, with second-year respondents sharing their experiences with first-year peers, many of the open-response comments are framed as advice.

The study combined data from Phase $1(n=37)$ with data from a second staff-run phase of the study. Minor amendments were made to the questionnaire and recruitment documentation and it was administered to both first-year and second-year students after their 2015 placement. Phase 2 achieved a 66\% response rate $(n=63)$ resulting in an overall response rate of $70 \%(n=100)$ across the two phases. Univariate and bivariate analyses of the combined database were undertaken by the authors using IBM SPSS Statistics version 20 .

\section{Limitations}

A methodological limitation of this study was its cross-sectional design and it would have undoubtedly benefitted from a longitudinal element that would have facilitated pre- and post-questioning as opposed to retrospective questioning. The validity of data would have been increased had a correlation with academic results and triangulation with responses from other members of the placement learning team been available. However, a collection of identifiable data would undoubtedly have impacted on ethical considerations and response rates. The single-school convenience sample used in this study also represents a methodological limitation as it may not fully represent practice learning in the profession as a whole.

\section{Findings}

Students were asked to rate learning support tools in terms of their usefulness and the frequency with which they were used during placement (Table 1). Bivariate analysis of the usefulness and frequency of use yielded clusters ranging from mainstay tools to tools which are infrequently used and not valued. The five mainstay tools of learning on placement which were considered very useful and were used at least weekly included a mix of dyadic and independent learning tools: observing others at work, informal supervision, co-working, increased responsibility/independent work and critiquing your 
Table 1. Student rating of frequency of use and usefulness of learning support tools

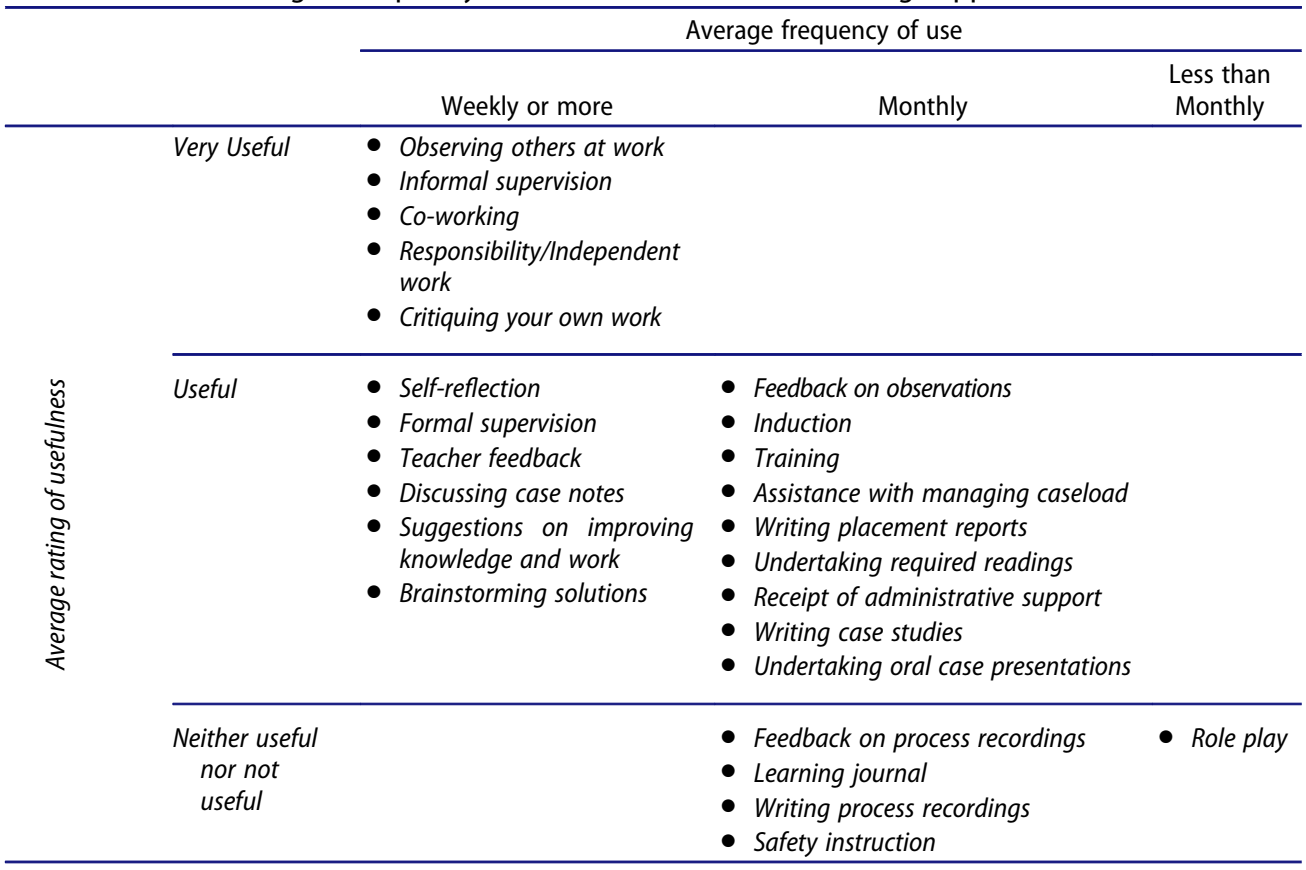

own work. It is perhaps not surprising, but nonetheless noteworthy, that three of the five mainstay tools relate to engagement with direct work with clients: observation, coworking and responsibility/independent work. These clearly underline the importance of exposure to direct work with clients over and above other learning tools.

\section{Social work cases}

\section{Observation}

Students agreed, almost unanimously $(\mathrm{n}=87,99 \%)$, that observing social workers was very useful $(n=74)$ or useful $(n=13)$. It was among the more frequently used tools and many were given the opportunity to observe others at work on a daily ( $n=43,48 \%)$ or weekly basis $(\mathrm{n}=28,31 \%)$. A response to an open question for example recounted

Observing or shadowing other probation officers during my first few days [was useful]. It was useful to observe various counselling styles and the various teams in Probation i.e. homeless offenders' team, circuit court team, young people's probation team, community service team, assessment team etc.

\section{Co-working}

Another valued learning support tool was co-working. It was considered very useful or useful by $93 \%(n=82)$. While some students were afforded the opportunity to co-work on a daily basis $(n=30,33 \%)$ the majority had the opportunity at least weekly $(n=40,44 \%)$. As one student advised their peers:

Make sure you put yourself forward to co-work with people and get involved with the agency you are with. The time goes by so quick. Don't be afraid to ask questions in the 
agency remember it is about you learning new things and it is your first placement. Enjoy it, soon you will be back in college again ...

\section{Working independently}

Increased responsibility or independent work was available to a third $(\mathrm{n}=30)$ of students on a daily basis and to half $(\mathrm{n}=48)$ on a weekly basis. Those who received increased responsibility/independent work less frequently were more likely to have had less frequent opportunities for observing other social workers and co-working. However, these differences were not statistically significant.

\section{Supervision and feedback}

Practice teachers in this study were contracted to provide a minimum of $1.5 \mathrm{~h}$ of formal supervision per week, with most providing significant amounts of additional informal supervision.

\section{Supervision: informal and formal}

Informal supervision was the most frequently availed of the tool with $90 \%(\mathrm{n}=85)$ occurring weekly or on a daily basis $(n=57,60 \%)$. Students clearly appreciated this support to learning, rating it as very useful $(n=72,77 \%)$ or useful $(n=17,18 \%)$. Perhaps of concern is the finding that four students received no informal supervision. However, it is worth pointing out that these students received formal supervision weekly $(\mathrm{n}=3)$ or monthly $(\mathrm{n}=1)$.

Given the ratings afforded to informal supervision it is somewhat surprising that formal supervision was less valued $(\mathrm{Z}=-3.052, \mathrm{P} \leq .01)$. Formal supervision was considered very useful by $62 \%(\mathrm{n}=58)$ and useful by $30 \%(\mathrm{n}=28)$ of the students. This may be partly attributable to the less frequent occurrence of formal supervision $(\mathrm{Z}=-4.683, \mathrm{P} \leq .001)$ with comparable weekly supervision $(n=80,88 \%)$ but notably less daily supervision $(n=4,4 \%)$.

\section{Feedback \& suggestions for practice}

Four feedback tools were included in the survey: general practice teacher feedback, suggestions on how to improve knowledge and work, feedback on observations on the student's work, and feedback on process recordings. Although sometimes considered an old-fashioned method, process recordings are, as Fox and Gutheil (2000, p. 40) note, intended to enhance learning and develop a knowledgeable, skilled and, ultimately, an autonomous professional social worker who examines his/her practice in a systematic, objective and critical way. The more broad-based teacher feedback and suggestions for improving work were considered more useful and were more frequently received. A clear majority of students received feedback from their practice teachers on a daily $(\mathrm{n}=35,35 \%)$ or weekly $(\mathrm{n}=48,50 \%)$ basis. This feedback was considered very useful by $63 \%(\mathrm{n}=60)$ and useful by $25 \%(\mathrm{n}=24)$.

He was able to give me honest feedback about areas that I needed to improve on. He had a great skills base and was able to tell me about techniques that work.

[he was] giving me a different way of interpreting what was happening, especially around my emotional processing of certain cases; ways of reframing cases; providing a supportive learning 
environment in which to learn and one in which I felt it was ok to make mistakes ... it gave me confidence in myself that I could do the job.

Respondents identified multiple valuable aspects of their practice teacher's feedback. Most common among these was advice on ways of working or how to take the next step in a case.

It was most useful to hear his thoughts on what I should do and informing me of what services and resources are available. There were many things I didn't know were out there that he or other colleagues informed me about.

She was able to guide me appropriately and get me to really question the complex situations in my cases and get me to figure out what I think I should do.

Telling me just to listen to the client and not to focus too much on completing the assessment.

Similarly, common among responses was the value of encouragement to be self-reflective and discuss cases $(\mathrm{n}=15,19 \%)$. The constructive nature of the feedback also featured in a number of responses:

It was always constructive. If there was something I needed to improve upon (e.g. allowing for silence more), he would ensure that he would explain why it was important and give examples of ways to implement it better.

She focused on the positives and highlighted what I did that worked and encouraged me to always try and improve on what was effective with clients. The feedback was always honest and constructive. she always followed up to see if I agreed/disagreed with the feedback. We would tease out any aspects of my practice that might have needed to be improved on and why it needed to be improved on, why I was practicing in a certain way and how I can overcome it, so I was always very clear on how to develop and improve my skills.

The value of positive reinforcement $(n=6)$ encouragement and confidence building was echoed in open responses by a number of respondents $(n=12)$. Other useful aspects of practice teacher's feedback included challenging assumptions and understandings $(n=7)$; linking theory and practice $(n=7)$ advice and help with written work $(n=6)$ and the practice teacher's knowledge and skills $(n=4)$. Help with planning and prioritizing $(n=3)$; recommended readings and resources $(n=4)$; opportunities for independent work/observation $(n=6)$; being appreciated $(n=1)$; thinking on one's feet $(n=1)$; and use of language $(n=2)$. However, some made reference to the impact of negative criticism $(n=3)$.

[There was] nothing useful about my practice teacher's feedback. Constant focus on mistakes, which were not tolerated. No constructive feedback was provided; just received criticism. It appeared that I was expected to operate at the level of an experienced practitioner within that organisation.

Students appeared to value suggestions about how to improve their knowledge and practice with $90 \%(\mathrm{n}=85)$ rating these as very/useful and $80 \%(\mathrm{n}=76)$ receiving such suggestions on at least a weekly basis.

Feedback on observations of students' work, although considered useful/very useful by $88 \%$ of respondents, was notably less likely to be rated as very useful ( $\mathrm{n}=45,47 \%$ ) than the type of more broad-based type of feedback discussed above. However, it was also less frequently available to students $(\mathrm{Z}=-6.065, \mathrm{P} \leq .001)$. Feedback on written process recordings was rated as less useful than the other three types of feedback. On average it 
was rated as 'neither useful nor not useful'. It was also received notably less frequently than other types of feedback, typically being provided monthly.

\section{Reviewing case material}

Many students found a discussion about case material helpful. These include 'brainstorming' solutions, and the use of process recordings. The most frequently used and most useful of these learning tools was review and/or discussion of case notes.

He would always challenge my perception of thinking about situations with clients, and reminding me that many of my clients have complex needs and the solution wasn't always straight forward while trying to link theory to practice and skills with each individual client and asking for my feedback with clients and potential ethical dilemmas that can arise.

Discussions of cases took place on at least a weekly basis for $73 \%(\mathrm{n}=66)$ and 'brainstorming' solutions were considered very useful $(n=41,47 \%)$ or useful $(n=32,37 \%)$ by a large number of students and was used at least weekly by $65 \%(n=60)$ of students.

\section{Induction, training and safety instruction}

All but two students received induction (although both of these students did receive training) which was considered useful/very useful by $71 \%(n=66)$ in comparison to $72 \%$ who found training useful. Safety instruction provided monthly was not available to a fifth of students and was considered, on average 'neither useful nor not useful', notably less useful than induction $(Z=5.465, P \leq .001)$ or training $(Z=6.278, P \leq .001)$.

\section{Reflective practice: self-reflection and critique}

Less than half $(\mathrm{n}=43,47 \%)$ of the students took time to critique their own work on a daily basis although a further $40 \%(\mathrm{n}=36)$ did so at least weekly. A minority $(\mathrm{n}=12,13 \%)$ critiqued their own work monthly or less. This tool was rated as very useful by $62 \%(n=55)$ and useful by $33 \%(n=29)$. Self-reflection was undertaken with a similar frequency to critiquing one's own work-daily by $44 \%(n=40)$ and weekly by $46 \%(n=42)$. However, self-reflection was considered marginally less useful.

\section{Less useful student-driven tools}

A number of other learning supports were viewed to be less helpful, including the writing of placement reports and case studies, required readings and oral case presentations. Learning journals and process recordings were typically employed on a monthly basis and were rated as 'neither useful nor not useful'. The following response, however, explains how one student found the reflective journal helped:

Even though it was not something that I had anticipated would be useful, the use of a reflective journal was really beneficial to me. I did not have the best time on placement with regards to my practice teacher so it helped me to write down what I was learning despite the struggles that I had which helped me to remain positive throughout placement. 


\section{Additional supports}

Additional supports identified by students included practice teacher and colleague provision of assistance in managing caseloads and also the assistance provided by administrative staff. These additional supports were rated as 'useful' and were only used on average monthly. Role play was the least frequently used learning tool, being used on average less than monthly.

\section{Other learning tools}

A fifth of respondents $(n=22)$ identified other learning tools that they believe would have facilitated their learning. These spanned a wide range of suggestions. An emerging theme $(\mathrm{n}=8)$, albeit focused on different aspects of social work practice, was the provision of, and advance practice of using, for example, care planning sheets; sample case notes; court reports; assessment frameworks; or use of a Kolb (1984) learning cycle in supervision.

My practice teacher provided me with copies of example reports and case notes (these were John Doe cases as opposed to real people's) which included all of the protocols deemed best practice in order to aid my writing.

More direct work and increased independent practice $(n=5)$ were suggested.

I would have liked more independent work, my practice teacher insisted on being involved in all of my cases on some level and I feel I would have learned more had I been left alone in some instances. Although I did appreciate his assistance and guidance.

being allowed to learn through making mistakes allowing learning to take place through practice teacher explaining how to do things better by not having every minor error pointed out and made bigger by having a practice teacher who knew what she was doing.

Those who were fortunate enough to have this opportunity for direct work spoke of its value.

I do feel that the biggest learning opportunity for me was being charg[ed] with facilitating a group and co-working this with another student. Huge learning curve and a lot of fun!!!

More attendance/engagement at meetings $(n=4)$ and more shadowing $(n=3)$ were also mooted

Allowed attend more meetings and home visits with my practice teacher and been able to observer how he interacted with clients.

as constructive feedback from practice teachers.

Students perceived the preeminent value of the mid-placement university call-back day to be the opportunity for them to catch up, talk to and get support from their peers $(n=30,45 \%)$. Indeed, this was the case, regardless of whether respondents found the day useful or not. Students valued the opportunity to listen to, discuss, compare and learn from each other's placements $(n=19,28 \%)$, experiences $(n=15,22 \%)$ and cases $(n=3,5 \%)$.

I was able to understand how others were getting on in placement and if they had any struggles with service users that I had.

The day also provided an opportunity to ask questions, get reassurance from lecturers $(n=2)$ and reflect on placement $(n=3)$. 
[it was] useful to reflect on what you had learned so far as when you are on placement you are too busy to really think too much about what you are doing - great to catch up with peers and hear their experiences of placement-Useful for linking theory to practice.

Although students valued the opportunity to 'catch up' with peers, they were generally critical of the content of teaching on the call-back day, but there was little consensus about what improvements could be made, but the idea of having a greater opportunity to air/discuss issues from placement was often made.

talking about things with people that you are sure nobody else will hear in your placements. Baring it all out [was useful].

\section{Skills development}

Students identified a range of skills that they felt had been developed on placement. These included the use of reflective approaches $(n=10)$ :

He taught me to implement a 'what I did well' and 'what I could do better' approach to reflection, which ensured that the good work I was doing was always acknowledged too instead of constantly critiquing myself which can get a bit overwhelming.

That she challenged me to slow down and take a reflective piece to my placement, she was able to praise me for work that I had done in which I wouldn't see the substantial work that I completed.

Writing skills $(\mathrm{n}=7)$ :

I had never written or seen court reports before this placement and my practice teacher helped me and I increased in learning how to put together formal reports, including the correct language to use when giving guidance to a Judge.

Others included communicating $(n=6)$ and listening $(n=5)$ skills; case management $(n=5)$; relationship and rapport building; observation skills; counseling; information gathering; preparation; self-care/protection; resilience; when to disengage. The growth in other skills and values (being non-judgmental; authoritative; confident; innovative; empathetic; supportive; constructive; respectful; honest; open; truthful; dedicated; and non-presumptive) were also mentioned:

You learn so much from watching you practice teacher: the fact she was interested in her job and cared for it. Her demeanour with clients, the importance of building that relationship even though you were there for assessment purposes.

A number of practice teachers were clearly inspirational, imparting a dedication which does not lend itself to a list of imparted skills.

My practice teacher would go to the absolute end of the earth for a client; she stopped at nothing. I will always remember that of her; she would spend the time with clients and get them anything they needed that she had the power to get for them.

\section{Placement outcomes}

The 'success' of placements was measured using two dependent variables: student's overall satisfaction with the placement and the student's perception of their learning. 
Half of the students (50\%) were 'very satisfied' and a further $40 \%$ 'satisfied' with their practice placement (Flanagan \& Wilson, 2018). The majority of students $(n=47,48 \%)$ indicated that they 'learnt a lot', on placement with a further third ( $\mathrm{n}=36,36 \%)$ reporting that they 'learnt more than expected' (Flanagan \& Wilson, 2018). These two dependent variables were strongly inter-correlated $\left(\mathrm{r}_{\mathrm{s}}=.625, \mathrm{P} \leq .001\right)$ indicating that personal learning played a significant part in determining satisfaction with placements, and vice versa. Correlation of these dependent variables with learning support tools allowed the authors to establish what role tools played in a positive placement evaluation (Table 2). Student-driven tools such as self-reflection, critiquing one's own work, writing placement reports, case studies, required readings, oral case presentations $\left(\mathrm{r}_{\mathrm{s}}=.280, \mathrm{P}<\right.$ .05 ), learning journals and process recordings were at best weakly correlated with learning and satisfaction. In contrast, the frequency of supports from others such as assistance with managing caseload $\left(\mathrm{r}_{\mathrm{s}}=.389, \mathrm{P}<.001 ; \mathrm{r}_{\mathrm{s}}=.464, \mathrm{P}<.001\right)$, administration support $\left(\mathrm{r}_{\mathrm{s}}=.440, \mathrm{P}<.001 ; \mathrm{r}_{\mathrm{s}}=.448, \mathrm{P}<.001\right)$ and brainstorming solutions $\left(\mathrm{r}_{\mathrm{s}}=.310, \mathrm{P}<\right.$ $\left..005 ; \mathrm{r}_{\mathrm{s}}=.339, \mathrm{P}<.005\right)$, were all positively correlated with learning and satisfaction. Although role-playing and discussing case notes did not make a significant contribution to overall satisfaction, greater frequency of role-playing was weakly associated with greater learning $\left(\mathrm{r}_{\mathrm{s}}=.261, \mathrm{P}<.05\right)$. Formal inputs such as induction, training and safety instructions did not make a contribution to perceived learning with, at best a moderate contribution to satisfaction by a useful induction program $\left(\mathrm{r}_{\mathrm{s}}=.339, \mathrm{P}<.001\right)$.

Somewhat counterintuitively, the perceived value of working with cases across the three levels of observing, co-working, and increased responsibility/independent work was not strongly correlated with perceived learning or overall satisfaction. Although greater frequency of co-working $\left(\mathrm{r}_{\mathrm{s}}=.250, \mathrm{P}<.01\right)$ and increased responsibility/independent work $\left(\mathrm{r}_{\mathrm{s}}=.316, \mathrm{P}<.001\right)$ were correlated with greater learning. Under the heading of 'supervision and feedback,' all tools were significantly correlated with both greater learning and higher satisfaction. The frequency of formal supervision had the weakest correlation with learning $\left(\mathrm{r}_{\mathrm{s}}=.268, \mathrm{P}<.001\right)$ and satisfaction $\left(\mathrm{r}_{\mathrm{s}}=.271, \mathrm{P}<.01\right)$ while the frequency of informal supervision was among the stronger correlations with both independent variables $\left(\mathrm{r}_{\mathrm{s}}=.446, \mathrm{P}<.005 ; \mathrm{r}_{\mathrm{s}}=.426, \mathrm{P}<.005\right)$. However, there was substantial multicollinearity between the frequency of various supervision/feedback tools, particularly with informal supervision, suggesting that informal supervision encapsulated the various types of feedback. Similarly, there was substantial multicollinearity between the value placed on various supervision or feedback tools indicting that the quality in supervision, both formal and informal, was associated with valuable feedback.

\section{Discussion}

The practice placement provides an opportunity for students to integrate theoretically and practice learning. It is well recognized within the research literature as being a central component of social work training (Bogo, 2015; Flanagan \& Wilson, 2018; Goodyear, 2014) as it is where students have the first opportunity to put their newly acquired knowledge into practice with actual clients. Placement is the forum through which many students first observe social work in practice. So not only are students often only seeing what social work in action looks like for the first time, but also observing what professional social work practice looks like. Findings from our study indicate that students recognized the act of 
Table 2. Spearman's correlation between tools and ratings of overall satisfaction and perceived level of practice learning on placement $(\mathrm{N}=100)$

\begin{tabular}{|c|c|c|}
\hline & \multicolumn{2}{|c|}{ Spearman's rho } \\
\hline & $\begin{array}{l}\text { Q3 Rating of } \\
\text { satisfaction with } \\
\text { placement? }\end{array}$ & $\begin{array}{l}\text { Q4 Perceived level of } \\
\text { practice learning on } \\
\text { placement? }\end{array}$ \\
\hline Q3 Rating of satisfaction with placement? & 1.000 & $.625^{* *}$ \\
\hline Q4 Perceived level of practice learning on placement? & $.625^{* *}$ & 1.000 \\
\hline Q10a Frequency of formal supervision & $.271^{* *}$ & $.268^{* *}$ \\
\hline Q10b Frequency of informal supervision & $.426^{* *}$ & $.446^{* *}$ \\
\hline Q10c Frequency of induction & $.239^{*}$ & .081 \\
\hline Q10d Frequency of Practice Teacher's feedback & $.411^{* *}$ & $.465^{* *}$ \\
\hline Q10e Frequency of feedback on process recordings & $.420^{* *}$ & $.414^{* *}$ \\
\hline Q10f Frequency of feedback on observations of your work & $.360 * *$ & $.527^{* *}$ \\
\hline $\begin{array}{l}\text { Q10g Frequency of suggestions on how to improve your knowledge and } \\
\text { practice }\end{array}$ & $.468^{* *}$ & $.476^{* *}$ \\
\hline Q10h Frequency of safety instruction & $.302^{* *}$ & $.273^{* *}$ \\
\hline Q10i Frequency of training & .193 & .128 \\
\hline Q10j Frequency of assistance in managing your caseload & $.464^{* *}$ & $.389^{* *}$ \\
\hline Q10k Frequency of administrative support & $.448^{* *}$ & $.440^{* *}$ \\
\hline Q11a How useful was formal supervision & $.541^{* *}$ & $.451^{* *}$ \\
\hline Q11b How useful was informal supervision & $.502^{* *}$ & $.436^{* *}$ \\
\hline Q11c How useful was induction & $.389^{* *}$ & .205 \\
\hline Q11d How useful was Practice Teacher's feedback in general & $.715^{* *}$ & $.535^{* *}$ \\
\hline Q11e How useful was feedback on process recordings & $.447^{* *}$ & $.352^{* *}$ \\
\hline Q11f How useful was feedback on observations of your work & $.482^{* *}$ & $.365^{* *}$ \\
\hline $\begin{array}{l}\text { Q11g How useful were suggestions on how to improve your knowledge \& } \\
\text { practice }\end{array}$ & $.564^{* *}$ & $.442^{* *}$ \\
\hline Q11h How useful was safety instruction & $.339 * *$ & $.220^{*}$ \\
\hline Q11i How useful was training & $.239^{*}$ & .127 \\
\hline Q11j How useful was assistance in managing your caseload & $.489^{* *}$ & $.369^{* *}$ \\
\hline Q11k How useful was administrative support & $.371^{* *}$ & $.352^{* *}$ \\
\hline Q16a How frequently did you review/discuss of case notes as a learning tool & .024 & .067 \\
\hline Q16b Frequency of brainstorming solutions as a learning tool & $.339 * *$ & $.310^{* *}$ \\
\hline Q16c Frequency of writing process recordings & $.256^{*}$ & $.212^{*}$ \\
\hline Q16d Frequency of role-playing/rehearsal & .146 & $.261^{*}$ \\
\hline Q16e Frequency of self-reflection & .030 & .005 \\
\hline Q16f Frequency of maintaining a learning journal & -.056 & -.146 \\
\hline Q16g Frequency of critiquing your own work & .000 & .049 \\
\hline Q16h Frequency of observing others at work & .123 & .129 \\
\hline Q16i Frequency of co-working & $.240^{*}$ & $.250^{*}$ \\
\hline Q16j Frequency of required readings & .033 & .116 \\
\hline Q16k Frequency of case studies authored by you & -.111 & -.034 \\
\hline Q16L Frequency of oral presentations of casework by you & $.280^{* *}$ & .136 \\
\hline Q16m Frequency of preparation of fieldwork placement reports & .200 & .197 \\
\hline Q16n Frequency of increasing levels of responsibility/independent work & $.205^{*}$ & $.316^{* *}$ \\
\hline Q17a Usefulness of review/discussion of case notes & .084 & .146 \\
\hline Q17b Usefulness of brainstorming solutions & .077 & .098 \\
\hline Q17c Usefulness of writing process recordings & .013 & -.046 \\
\hline Q17d Usefulness of role playing/rehearsal & .099 & .082 \\
\hline Q17e Usefulness of self-reflection & .176 & .052 \\
\hline Q17f Usefulness of maintaining a learning journal & -.063 & -.168 \\
\hline Q17g Usefulness of critiquing your own work & .176 & .083 \\
\hline Q17h Usefulness of observing others at work & $.226^{*}$ & .154 \\
\hline Q17i Usefulness of co-working & .169 & .127 \\
\hline Q17j Usefulness of required readings & .090 & .204 \\
\hline Q17k Usefulness of case studies authored by you & .056 & -.040 \\
\hline Q17L Usefulness of oral presentations of casework by you & .196 & .190 \\
\hline Q17m Usefulness of preparation of fieldwork placement reports & $.220^{*}$ & $.229^{*}$ \\
\hline Q17n Usefulness of increasing levels of responsibility/Independent work & $.275^{* *}$ & $.244^{*}$ \\
\hline
\end{tabular}

**. Correlation is significant at the 0.01 level (2-tailed); ${ }^{*}$. Correlation is significant at the 0.05 level (2-tailed). 
observation and shadowing social work practitioners was the most valuable for their learning and, although they did not explicitly link these tools to the formation of their professional identity, it was clear that it contributed to their development of self as a social worker.

Practice educators have an ethical responsibility to provide students on placement with appropriate learning experiences to gain the skills for future social work practice. As well as observing and shadowing practice, students need opportunities to carry out direct work with clients, within their capabilities, and also have access to regular constructive feedback on their placement performance. Focusing on the mainstay tools identified in this study, students indicated that they did receive the opportunity to observe, co-work, and work independently and this was highly valued. As is well outlined in literature, supervision is core to the educational experience of students (Cleak et al., 2015; Goodyear, 2014; Kourgiantakis et al., 2019). The current study concurred with this, finding that supervision and feedback from practice teachers had the biggest impact on both levels of placement learning and satisfaction. However, as Kourgiantakis et al. (2019) noted, little is known about the mechanism by which supervision enhances student learning. This study did, however, tap into the perceived value of informal supervision, echoing Lefevre's (2005) finding of the importance of practice teacher availability to the student as well as providing an encouraging and collaborative learning environment. Once again, this underlines the crucial contribution of supervisors to practice learning.

Of interest in this study was the finding that students attached much greater importance to the role of external contributors to their learning, such as their practice teachers or other team members. This appears to have overshadowed how they ranked the importance of student-driven tools such as required readings, writing case studies, oral case presentations, self-critique, and self-reflection. Typically, learning on placement is understood as being rooted in theories of adult learning, where the student is seen as being actively engaged in their learning and accepts responsibility for it (Nixon \& Murr, 2006). This was an unusual finding in light of the fact that students recounted the fact that practice teachers encouraged the use of self-reflection and the students themselves acknowledged self-reflection as being a valuable skill to acquire. The apparent difference between the role of teacher-led tools, assistance tools, and student-driven tools in overall placement satisfaction and learning suggests that greater emphasis needs to be placed on the importance of self-directed learning on placement, and also within the university setting. Students would benefit from having a greater recognition of the importance of their own experience and knowledge and how this can direct their engagement in self-directed learning.

\section{Conclusions}

The well-documented centrality of observation, direct work, supervision, and feedback is confirmed in this study as the three levels of working with cases, observing, co-working and increased responsibility/independent work, were among the most highly valued and most frequently used tools. Critiquing one's own work and informal supervision were also identified as key tools, with informal supervision being the most frequently availed of the tool. It seems likely that the lower value rating attributed to formal supervision may reflect its less frequent occurrence. Engaging the less dominant voice of the student has 
also yielded valuable insights. Most notably, the extent to which supervision overshadows the importance of autonomous learning in students' eyes has been foregrounded here. This finding underlines the need for social work educators to instill in students a confidence and trust in the value of their own role in learning, imbuing them with a sense of responsibility for their own learning. Adult learning requires students to be active participants in their learning and whilst students will continue to have external learning tools at their disposal, they need to be proactive in both identifying and taking responsibility for learning. Social work education is required to provide students with knowledge and teach them the relevant skills to enter the profession. This value on autonomous learning is a vital preparation for professional lives.

\section{Disclosure statement}

No potential conflict of interest was reported by the authors.

\section{Notes on contributors}

Elaine Wilson is an Assistant Professor in the School of Social Policy, Social Work and Social Justice, University College Dublin where she is Co-Director of the Professional Masters of Social work and Director of Professional Practice. Her research interests include social work education and adult learning as well as the psycho-social needs of people with cancer and the social construction of illness.

Niamh Flanagan is an Assistant Professor in the Department of Applied Social Studies, Maynooth University. Her research interests include social work research and education, in particular the role of educational technology, information behaviour and the evidence-base of policy and practice.

\section{ORCID}

Elaine Wilson (iD) http://orcid.org/0000-0002-1916-9776

Niamh Flanagan (D) http://orcid.org/0000-0003-1431-7132

\section{References}

Barretti, M. A. (2009). Ranking desirable field instructor characteristics: Viewing student preferences in context with field and class experience. The Clinical Supervisor, 28(1), 47-71.

Bellinger, A. (2010). Talking about (Re)generation: Practice learning as a site of renewal for social work. British Journal of Social Work, 40, 2450-2466.

Bogo, M. (2015). Field education for clinical social work practice: Best practices and contemporary challenges. Clinical Social Work Journal, 43(3), 317-324.

Bogo, M., \& McKnight, K. (2006). Clinical supervision in social work: A review of the research literature. The Clinical Supervisor, 24(1-2), 49-67.

Bogo, M., \& Sewell, K. (2019). Introduction to the special issue on field education of students. Clinical Social Work Journal, 47(1), 1-4.

Chui, W. H. (2009). First practice placement. The Journal of Practice Teaching and Learning, 9(2), $10-32$.

Clare, B. (2007). Promoting deep learning: A teaching, learning and assessment endeavour. Social Work Education, 26(5), 433-446.

Cleak, H., Hawkins, L., Laughton, J., \& Williams, J. (2015). Creating a standardised teaching and learning framework for social work field placements. Australian Social Work, 68(1), 49-64. 
Cleak, H., \& Smith, D. (2012). Student satisfaction with current models of field placement supervision. Australian Social Work, 65(2), 243-258.

Fernandez, E. (1998). Students perceptions of satisfaction with the practice curriculum. Social Work Education, 23(3), 81-89.

1st Year M.Soc.Sc. (Social Work) Students, Flanagan, N., \& Wilson, E. (2015, June 5). What facilitates learning on placement? Unpublished poster presentation at: Irish Association of Social Workers Annual Conference, Dublin, Ireland.

Flanagan, N., \& Wilson, E. (2018). What makes a good placement? Findings of a social work student-to-student research study. Social Work Education, 37(5), 565-580.

Fortune, A. E., McCarthy, M., \& Abramson, J. S. (2001). Student learning processes in field education: Relationship of learning activities to quality of field instruction, satisfaction, and performance among MSW students. Journal of Social Work Education, 37(1), 111-124.

Fox, R., \& Gutheil, I. A. (2000). Process recording. Journal of Teaching in Social Work, 20(1-2), $39-55$.

Goodyear, R. K. (2014). Supervision as pedagogy: Attending to its essential instructional and learning processes. The Clinical Supervisor, 33(1), 82-99.

Joubert, L., Hebel, L., McNeill, A., Firth, S., McFadden, E., \& Hocking, A. (2017). Teaching research in social work through academic practitioner partnerships: Knowledge, competency and confidence. Advances in Social Work and Welfare Education, 19(1), 37-48.

Kolb, D. (1984). Experiential learning. Englewood Cliffs, NJ: Prentice Hall.

Kourgiantakis, T., Sewell, K., \& Bogo, M. (2019). The importance of feedback in preparing social work students for field education. Clinical Social Work Journal, 47(1), 124-133.

Lefevre, M. (2005). Facilitating practice learning and assessment: The influence of relationship. Social Work Education, 24(5), 565-583.

Mac Dermott, D., \& Campbell, A. (2016). An examination of student and provider perceptions of voluntary sector social work placements in Northern Ireland. Social Work Education, 35(1), 31-49.

McIntyre, G., \& Paul, S. (2013). Teaching research in social work: Capacity and challenge. British Journal of Social Work, 43(1), 685-702.

McSweeney, F., \& Williams, D. (2018). Social care students' learning in the practice placement in Ireland. Social Work Education, 37(5), 581-596.

Miller, J., Kovacs, P., Wright, L., Corcoran, J., \& Rosenblum, A. (2005). Field education: Student and field instructor perceptions of the learning process. Journal of Social Work Education, 41(1), 131-145.

Mumm, A. (2006). Teaching social work students practice skills. Journal of Teaching in Social Work, 26, 71-89.

Nixon, S., \& Murr, A. (2006). Practice learning and the development of professional practice. Social Work Education, 25(8), 798-811.

Rawles, J. (2016). Developing social work professional judgement skills: Enhancing learning in practice by researching learning in practice. Journal of Teaching in Social Work, 36(1), 102-122.

Roulston, A., Cleak, H., \& Vreugdenhil, A. (2018). Promoting readiness to practice: Which learning activities promote competence and professional identity for student social workers during practice learning. Journal of Social Work Education, 25(2), 364-378.

Rubin, D., Robinson, B., \& Valutis, S. (2010). Social work education and student research projects: A survey of program directors. Journal of Social Work Education, 46(1), 39-55.

Simpson, D., Mathews, I., Croft, A., McKinna, G., \& Lee, M. (2010). Student views on good practice in social work education. Social Work Education, 52(4), 462-472.

Smith, D., Cleak, H., \& Vreugdenhil, A. (2015). “'What are they really doing?” An exploration of student learning activities in field placement. Australian Social Work, 68(4), 515-531.

Vayda, E., \& Bogo, M. (1991). A teaching model to unite classroom and field. Journal of Social Work Education, 27(3), 271-278.

Wilson, G. (2013). Preparing social workers for practice: Revaluating student learning needs. Social Work Education, 32(5), 590-606. 
Wilson, G., Walsh, T., \& Kirby, M. (2008). Developing practice learning: Student perspectives. Social Work Education, 27(1), 35-50.

Wulf-Andersen, T., Morgensen, K., \& Hjort-Madsen, P. (2013). Researching with undergraduate students: Exploring the learning potentials of undergraduate students and researchers collaborating in knowledge production. Journal of Research Practice, 9(2), M9. 